\title{
LED-based portable light source for photodynamic therapy
}

Chepurna, O., Grebinyk, A., Petrushko, Yu., Prylutska, S., Grebinyk, S., et al.

O. Chepurna, A. Grebinyk, Yu. Petrushko, S. Prylutska, S. Grebinyk, V. M. Yashchuk, O. Matyshevska, U. Ritter, T. Dandekar, M. Frohme, J. Qu, T. Y. Ohulchanskyy, "LED-based portable light source for photodynamic therapy," Proc. SPIE 11190, Optics in Health Care and Biomedical Optics IX, 111901A (20 November 2019); doi: 10.1117/12.2541774

SPIE. Event: SPIE/COS Photonics Asia, 2019, Hangzhou, China 


\title{
LED-based portable light source for photodynamic therapy
}

\author{
O. Chepurna ${ }^{\mathrm{a}, \mathrm{b}}$ A. Grebinyk ${ }^{\mathrm{c}, \mathrm{d}}$, Yu. Petrushko ${ }^{\mathrm{b}}$, S. Prylutska ${ }^{\mathrm{e}}$, S. Grebinyk ${ }^{\mathrm{c}}$, \\ V. M. Yashchuk ${ }^{\mathrm{e}}$, O. Matyshevska ${ }^{\mathrm{f}}$, U. Ritter ${ }^{\mathrm{g}}$, T. Dandekar ${ }^{\mathrm{d}}$, M. Frohme ${ }^{\mathrm{c}}$, \\ J. Qu ${ }^{\text {a* }}$, T.Y. Ohulchanskyy ${ }^{\text {a* }}$ \\ ${ }^{a}$ Key Laboratory of Optoelectronic Devices and Systems of Ministry of Education and Guangdong \\ Province, College of Physics and Optoelectronic Engineering, Shenzhen University, Shenzhen, \\ Guangdong Province, 518060, P. R. China \\ bSME "Fotonika Plus", Odeska 8, 18000, Cherkasy, Ukraine \\ cDivision Molecular Biotechnology and Functional Genomics, Technical University of Applied \\ Sciences Wildau, Hochschulring 1, 15745 Wildau, Germany \\ ${ }^{\mathrm{d} D e p a r t m e n t ~ o f ~ B i o i n f o r m a t i c s, ~ B i o c e n t e r, ~ U n i v e r s i t y ~ o f ~ W u ̈ r z b u r g, ~}$ \\ Am Hubland, 97074 Würzburg, Germany \\ ${ }^{\mathrm{e}}$ Taras Shevchenko National University of Kyiv, Volodymyrska 64, 01601 Kyiv, Ukraine

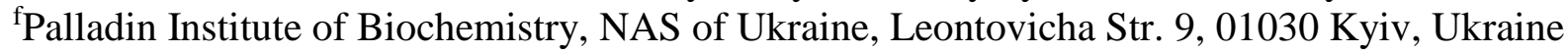 \\ g Institute of Chemistry and Biotechnology, University of Technology Ilmenau, Weimarer Straße 25 \\ (Curiebau), 98693 Ilmenau, Germany
}

\begin{abstract}
Photodynamic therapy (PDT) employs light activation of tissue-localized photosensitizer in an oxygen-dependent process which initiates oxidative stress, inflammation, and cell death. Laser systems, which are mostly used in PDT as light sources can be costly and oversized. light-emitting diodes (LEDs) equipment has a high potential to simplify technical part of phototriggered therapies and to reduce its costs. We develop the LED-based system that includes the control and irradiation units. The system provides the same power density at any irradiation point. Among the advantages of the device is a possibility to change the irradiation area and tune the irradiation dose. PDT experiments with cancer cells in vitro treated with two different photosensitizers demonstrated a possibility to use the developed LED-based system as a low-cost light source in PDT.
\end{abstract}

Keywords: light source, high power single chip LED, photodynamic therapy

\section{INTRODUCTION}

Photodynamic therapy (PDT) is an effective option for treatment of human malignancies, which involves three separately non-toxic components: light, photoactive substance (i.e., photosensitizer, PS) and molecular oxygen [1]-[3]. Light sources mostly used in PDT are laser systems, which are frequently technically complicated, costly and oversized [4], [5]. The main limitation of diode lasers, which are otherwise very convenient and reliable, is that they are singlewavelength devices, so that a separate unit is required for each photosensitizer [6], [7]. Introduction of light-emitting diodes as light sources in PDT has potential to simplify and significantly reduce cost of equipment, making PDT application more convenient for clinical use [8]-[10].

The major advantages of LEDs include high power output, capability for illuminating large areas, less hazardous, thermally non-destructive, less expensive and readily available [8], [11]. The use of LEDs is expected to promote PDT application, since they have a higher portability and extremely lower cost in comparison with lasers (classical PDT light sources) [10], [12].

*Correspondence: tyo@szu.edu.cn; jlqu@ szu.edu.cn 
Collateral damage to normal tissue can be minimized by increasing the selective accumulation of a photoactive agent in the tumor or other diseased tissue, and by delivering the light in a spatially confined and focused manner. Moreover, fractionation of light is a promising tool for the optimization of PDT, in order to select the most effective combination of a photoactive agent and the light conditions such as light wavelength and fluence [13], [14] which can be realized using sharp spectrum LEDs.

In this paper, we report the development of LED-based light source, which deliver the same power density at any illuminated point. In vitro PDT experiments with cancer cells in vitro treated with two different photosensitizers (berberine (Ber) [15], [16] or fullerene $\mathrm{C}_{60}$ [17]) demonstrated a possibility to use the developed LED-based low-cost light source in PDT.

\section{MATERIALS AND METHODS}

\subsection{Light sources}

High power LEDs are available in various colors (red, white, green, blue, yellow, etc.), which can be selected according to requirement. In this system, LEDs in the spectral range from 400 to $800 \mathrm{~nm}$, with a power of 5-290 mW, and a beam divergence angle of $55-65^{\circ}$ can be used. The fluorescence spectra of LEDs (purchased from Cree Inc., USA) were determined using spectrometer Ocean Optics USB4000 (Fig. 1).

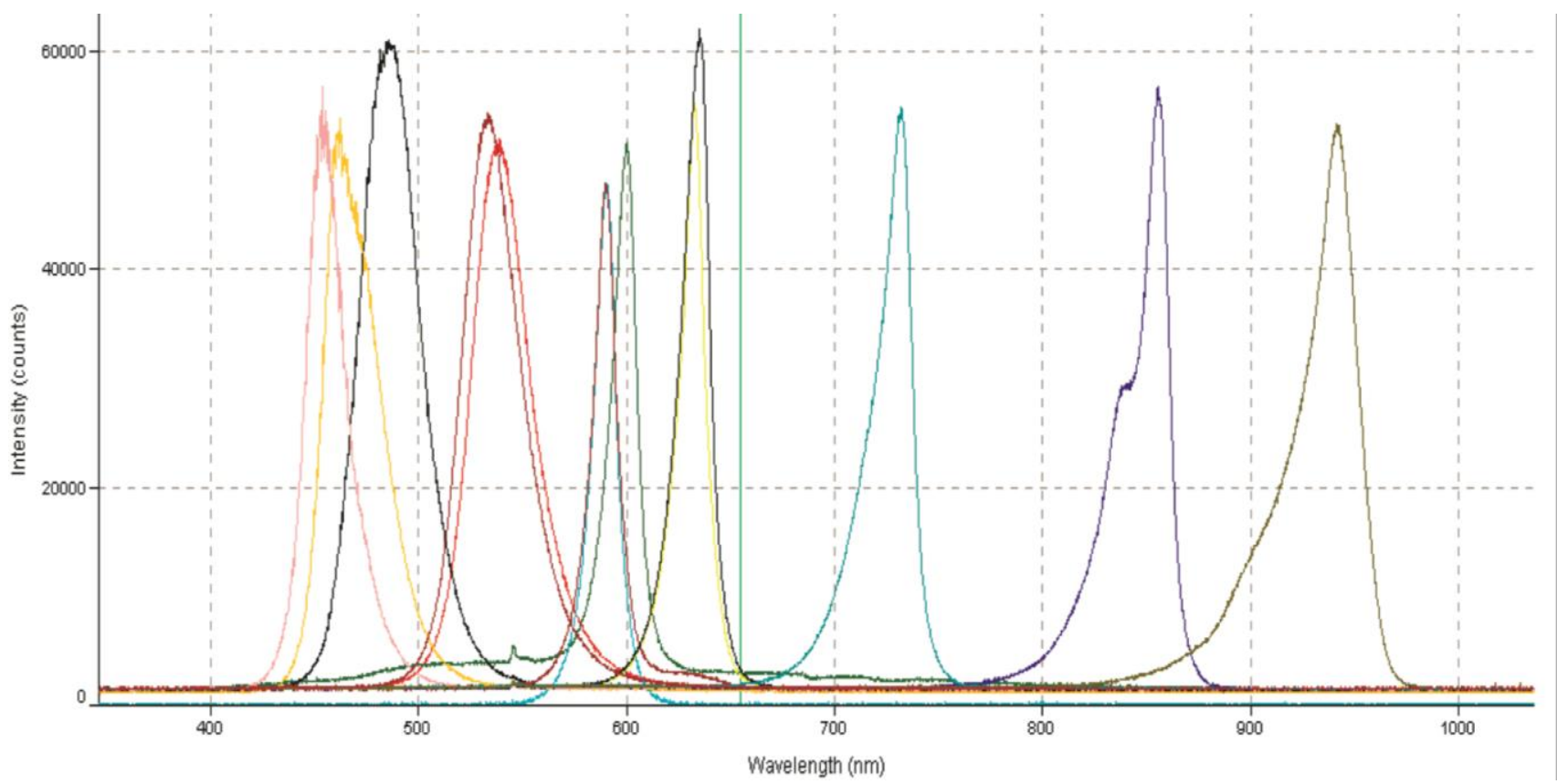

Figure 1. Fluorescence spectra of LEDs

The irradiation power of LED with the same current were determined by thermal sensor 10AP/N7Z02637 Ophir, Israel (Table 1). Taking into account demands of our recent experiments [17], we used two irradiation units with a single high power LED chip, $405 \mathrm{~nm}$ LED VL400-EMITTER or $515 \mathrm{~nm}$ LED APG2C1-515 (both from Roithner Lasertechnik $\mathrm{GmbH}$, Vienna, Austria), on a cylindrical heat sink.

The cascade of lens was designed to ensure high irradiation power density and even illumination for the irradiation spot. For the development of the optical cascade we applied an aspherical lens beam $(\mathrm{D}=13.0 \mathrm{~mm}, \mathrm{~h}=7.1 \mathrm{~mm}$ from Cree Inc., North Carolina, USA) for reducing the divergence angle of the, which allowed to focus all light to a second spherical lens with $35^{\circ}(50 \%$ int $)$ angle $(\mathrm{D}=16.4 \mathrm{~mm}, \mathrm{~h}=5.0 \mathrm{~mm}$ from Cree Inc., North Carolina, USA) to collimate output LED radiation and increase the power density. The diameter of the resulted collimated beam (and, correspondingly, the irradiated area) could be tuned from $25 \mathrm{~mm}$ to $35 \mathrm{~mm}$ by varying the distance between two lenses. Therefore, the largest distance can be used for design the largest diameter of irradiation zone. It parameters was used also for further requirements of the specification. 
For LED output power of $130 \mathrm{~mW}$ that results in a tunability of the output power density from $\sim 13.5 \mathrm{~mW} / \mathrm{cm} 2$ to $\sim$ $26 \mathrm{~mW} / \mathrm{cm} 2$. The same power density is delivered at any irradiated point.

Table 1. Information on video and audio files that can accompany a manuscript submission.

\begin{tabular}{|l|l|l|l|}
\hline \multicolumn{1}{|c|}{ LED } & \multicolumn{1}{|c|}{ Wavelength, nm } & Current, mA & Determining power, mW \\
\hline VL400-EMITTER & 405 & 350 & 290 \\
\hline APG2C1-515 & 515 & 350 & 150 \\
\hline $\begin{array}{l}\text { C3535MANF1- } \\
\text { E1H11N }\end{array}$ & 570 & 350 & 100 \\
\hline $\begin{array}{l}\text { XP-E XPERDO- } \\
\text { L1-0000-00701 }\end{array}$ & 620 & 350 & 112 \\
\hline APG2C1-660 & 660 & 350 & 220 \\
\hline $\begin{array}{l}\text { C3535XINA1- } \\
\text { E1D11N }\end{array}$ & 850 & 350 & 150 \\
\hline
\end{tabular}

\subsection{Chemicals}

RPMI 1640 cell medium, phosphate buffered saline (PBS), Fetal Bovine Serum (FBS), Penicillin/Streptomycin and Lglutamin were obtained from Biochrom (Berlin, Germany). 3-(4,5-dimethylthiazol-2-yl)-2,5-diphenyl tetrazolium bromide (MTT), Hoechst 33342, 2,7-dichlorofluorescin diacetate (DCFH-DA) and Berberine (Ber) was obtained from Sigma-Aldrich Co. (St-Louis, USA). Dimethylsulfoxide (DMSO) and trypan blue were obtained from Carl Roth GmbH + Co. KG (Karlsruhe, Germany). The pristine $\mathrm{C}_{60}$ aqueous colloid solution was prepared by $\mathrm{C}_{60}$ transfer from toluene to water using continuous ultrasound sonication as described by [18].

\subsection{Cell culture}

Human cancer T-cell lines CCRF-CEM (ACC 240) and Jurkat (ACC 282) were purchased from the Leibniz Institute DSMZ-German Collection of Microorganisms and Cell Cultures (Deutsche Sammlung von Mikroorganismen und Zellkulturen). Cells were maintained in RPMI 1640 medium, supplemented with 10\% FBS, 1\% Penicillin/Streptomycin and $2 \mathrm{mM}$ Glutamine. Cells were cultured in $25 \mathrm{~cm}^{2}$ culture flasks at a $37^{\circ} \mathrm{C}$ with $5 \% \mathrm{CO}_{2}$ in a humidified incubator Binder (Tuttlingen, Germany). The passaging was performed once cells reached $\approx 80 \%$. The number of viable cells was counted upon $0.1 \%$ trypan blue staining with a Roche Cedex XS Analyzer (Basel, Switzerland).

\subsection{Cell viability assay}

Cells were cultured in 96-well cell culture plates Sarstedt (Nümbrecht, Germany) for $24 \mathrm{~h}$ after seeding (10 4 cells/well). Then, the cell culture medium was replaced with medium containing Ber or $\mathrm{C}_{60}$ and cells were incubated for other 24 hrs. After $24 \mathrm{~h}$ incubation cells were washed with PBS and cells were irradiated with the developed LED-based system $\left(405 \mathrm{~nm} ; 108.3 \mathrm{~mW} / \mathrm{cm}^{2} ; 2,2.5,5,10\right.$ or $\left.25 \mathrm{~J} / \mathrm{cm}^{2}\right)$. PBS was replaced with the fresh medium immediately after irradiation. Control cells were incubated without any treatment or light irradiation. After $24 \mathrm{~h}$ ofincubation, cell viability was determined with colorimetric assay [19].

\subsection{Statistics}

All experiments were carried out with a minimum of three replicates. Data analysis was performed with the use of the GraphPad Prism 7 (GraphPad Software Inc., USA). Paired Student's t-tests were performed. Differences values p<0.01 were considered to be significant. 


\section{RESULTS AND DISCUSSION}

The Figure 2 shows a scheme of the developed LED-based light source. It consists of heat sink, LED and optical system.

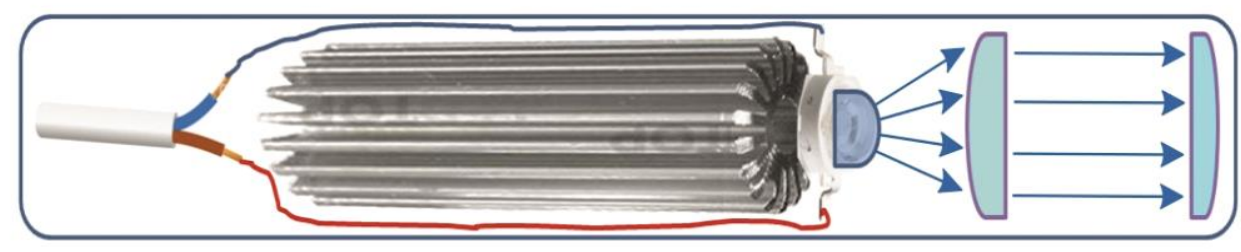

Figure 2. Construction scheme of the LED-based light source: spherical and aspherical lenses, LED, heated sink, wirings to power splay

A 3D model of mounting carcass was designed in 3D printer software (SOLIDWorks, Dassault Systems, MA, USA). The mounting carcass parts have been 3D-printed with polylactic acid at Ultimaker 2+ 3D printer (Utrecht, Netherlands). Other models of 3D printers are also possible to use. The plastic mounting carcass is composed of five parts that have been assembled according to Fig. 2.

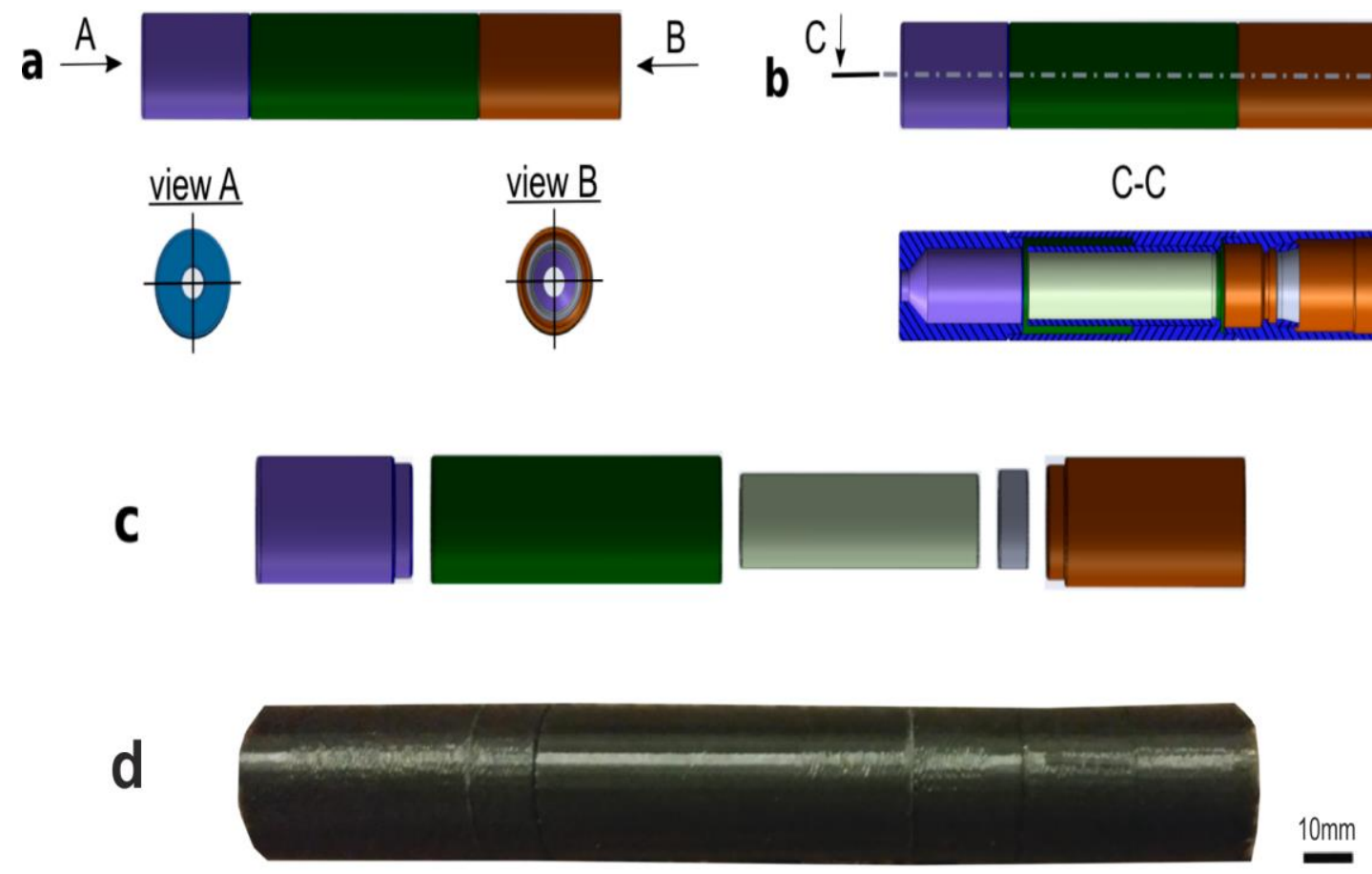

Figure 3. Plastic parts of LED light source: $a$ - main views, $b$ - cross section, $c$ - extended view; $d$ - photo of 3D printed plastic modeled-based light source.

The developed light source grants an opportunity to vary the evenly irradiated area; this is a major advantage of the system. The same power density is provided at any irradiated point, allowing for accurate and even delivery of the irradiation dose. As shown in the Figure 4 the relatively uniform distribution of power density was received (for the level 0.7). Measurements were performed on a specially equipped optical stand using the power meter device OMS-65 (Ukraine) with optical fiber (SMA-905, $1.5 \mathrm{~mm}, \mathrm{NA}=0.5$ ). Consequently, the optical elements greatly increase the efficiency of using LEDs irradiation and help to collimate irradiation in a narrower beam. 


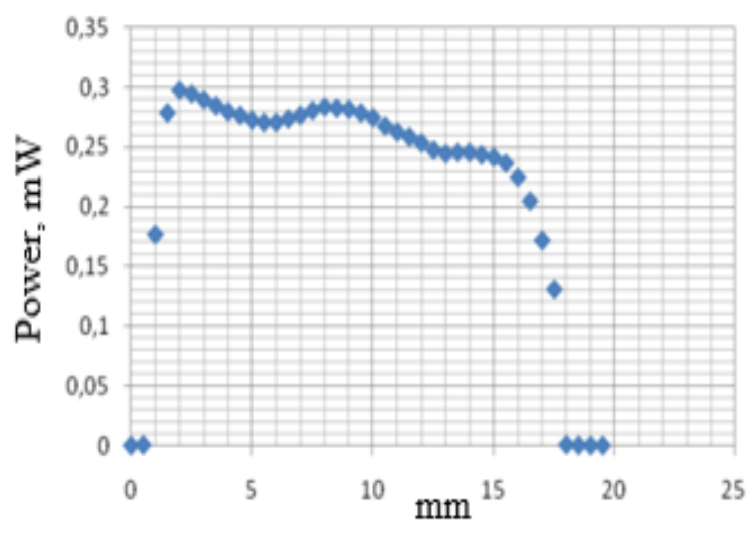

Figure 4. Power density distribution of LED-based light source after the optical lenses

To demonstrate the applicability of LED-based light source in PDT, experiments with PDT agents (Ber or $\mathrm{C}_{60}$ fullerene) treating cancer cells in vitro was conducted. The performance tests prove that the LED-based light source provides an adjustable, stable, wavelength-specific, homogeneous and large-area illumination for in vitro applications.
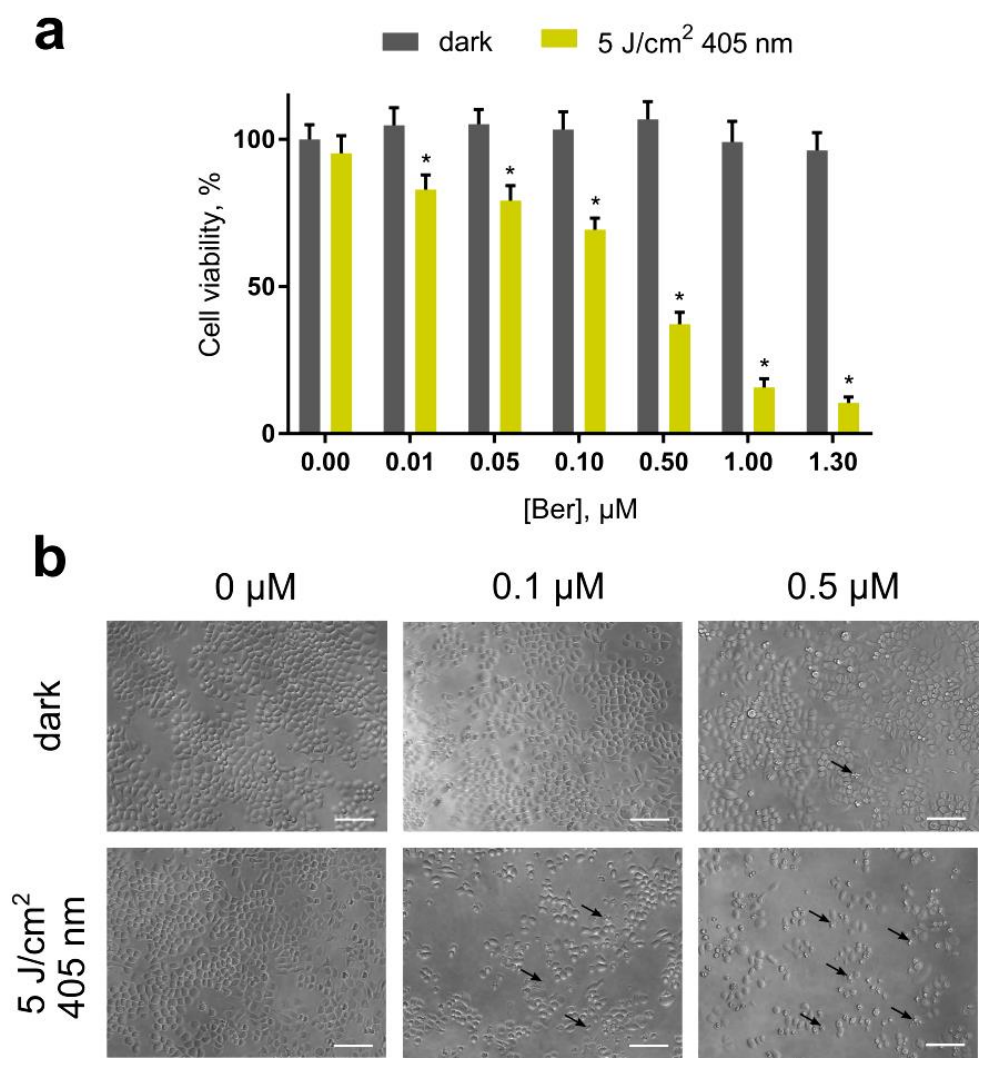

Figure 5. In vitro PDT of CCRF-CEM cells with Ber and $405 \mathrm{~nm}$ LED: a - Viability of CCRF-CEM cells, treated with 0-1.3 $\mu \mathrm{M}$ Ber and irradiated with $5 \mathrm{~J} / \mathrm{cm}^{2} 405 \mathrm{~nm}$ LED, ${ }^{*} \mathrm{p} \leq 0.01$ in comparison with the dark control; $\mathrm{b}-$ Morphological characterization under phase contrast microscopy of CCRF-CEM cells, treated with $0-0.5 \mu \mathrm{M}$ Ber and irradiated with 5 $\mathrm{J} / \mathrm{cm}^{2} 405 \mathrm{~nm} \mathrm{LED}$, scale bar $100 \mu \mathrm{m}$, black arrows point apoptotic bodies. 
The viability of CCRF-CEM cells, exposed to Ber at concentration ranging from 0 to $1.3 \mu \mathrm{M}$ in combination with 405 $\mathrm{nm}$ LED light irradiation was evaluated using MTT assay; the MTT results are shown in Fig. 5a. A considerable attention has been paid to identify Ber inhibiting potential on cancer cell [20]-[22]. Ber effect towards human leukemic CCRF-CEM cells was found to exhibit a dose- and time-dependent cytotoxicity in concentrations $\geq 3 \mu \mathrm{M}$. In the current study Ber concentrations from 0 to $1.3 \mu \mathrm{M}$ with none dark toxicity were chosen to assess its possible photosensitizing activity in vitro.

No significant effect of Ber introduced alone towards leukemic cell viability was detected, while the concentrationdependent toxic effect of the Ber under $5 \mathrm{~J} / \mathrm{cm}^{2} 405 \mathrm{~nm}$ LED light irradiation was observed (Fig. 5a). Thus, photoexcited 0.1 and $0.5 \mu \mathrm{M}$ Ber decreased CCRF-CEM cell viability to $69 \pm 4 \%$ and $37 \pm 4 \%$ correspondingly. As shown on Figure 5B, CCRF-CEM cells, exposed to photoexcited 0.1 and $0.5 \mu \mathrm{M}$ Ber, demonstrated a decrease of viable cells. Apart from the decreased cell number there were detected also visible changes in cell morphology. Thus, intense cell shrinkage and appearance of apoptotic bodies (Fig. 5b, black arrows) suggested apoptosis induction. Obtained data demonstrated that Ber treatment with $5 \mathrm{~J} / \mathrm{cm}^{2} 405 \mathrm{~nm}$ LED light irradiation exhibited significant cytotoxic effects against human leukemic cells.

$405 \mathrm{~nm}$ LED light irradiation was detected to have a slight effect on Jurkat cell viability (Fig. 6). Thus, 10 and $25 \mathrm{~J} / \mathrm{cm}^{2}$ light irradiation decreased cell viability to $89 \pm 6 \%$ and $76 \pm 5 \%$ correspondingly. Photoexcited $\mathrm{C}_{60}$ exhibited a pronounced toxic effect towards Jurkat cells that was dependent on the light fluence (Fig. 6). Cell viability was decreased to $60 \pm 5 \%$ and $38 \pm 4 \%$ under combinative treatment of $\mathrm{C}_{60}$ and $405 \mathrm{~nm}$ LED light irradiation at 10 and 25 $\mathrm{J} / \mathrm{cm}^{2}$ respectively.

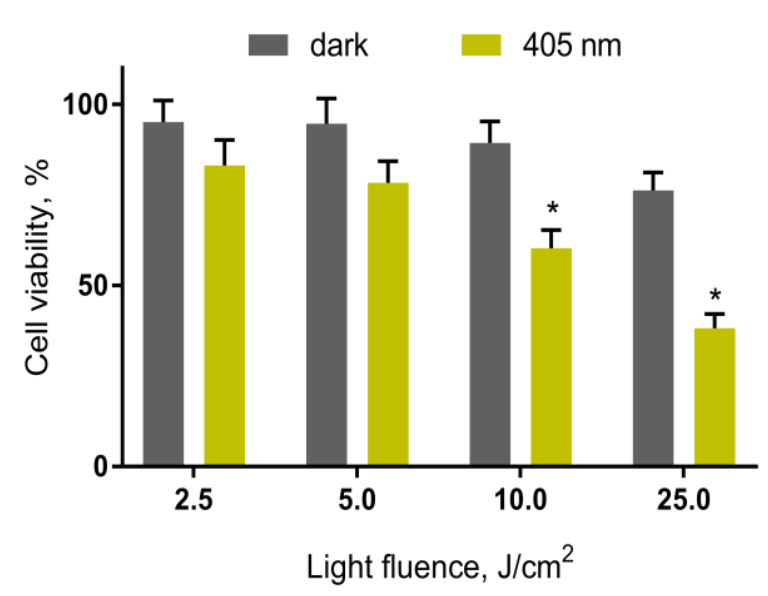

Figure 6. In vitro PDT of Jurkat cells with $20 \mu \mathrm{M} \mathrm{C}_{60}$ and $405 \mathrm{~nm} \mathrm{LED,} * \mathrm{p} \leq 0.01$ in comparison with the dark control.

\section{CONCLUSIONS}

In vitro PDT experiments with human leukemic cancer cells treated with Ber or $\mathrm{C}_{60}$ fullerene photosensitizers demonstrated the usability of the developed LED-based system for exciting the PS internalized by cells and inducing the PDT effect followed by cell death. The system was shown to provide the same power density at any irradiation point, allowing for accurate calculation and selection of the irradiation dose. We conclude that the developed LED-based system, which is low-cost and portable is a promising light source for application in PDT. 


\section{REFERENCES}

[1] T. J. Dougherty et al., "Photodynamic Therapy," JNCI J. Natl. Cancer Inst., vol. 90, no. 12, pp. 889-905, Jun. 1998.

[2] B. C. Wilson and M. S. Patterson, "The physics, biophysics and technology of photodynamic therapy," Phys. Med. Biol., vol. 53, no. 9, pp. R61-R109, May 2008.

[3] P. Agostinis et al., "Photodynamic therapy of cancer: An update," CA. Cancer J. Clin., 2011.

[4] R. R. Allison, "Photodynamic therapy: oncologic horizons," Futur. Oncol., vol. 10, no. 1, pp. 123-124, Jan. 2014.

[5] O. Chepurna et al., "Photodynamic therapy with laser scanning mode of tumor irradiation," in 16th Conference on Optical Fibers and Their Applications, 2015, vol. 9816, pp. 98161F-98161F-4.

[6] Z. Huang, "A Review of Progress in Clinical Photodynamic Therapy," Technol. Cancer Res. Treat., vol. 4, no. 3, pp. 283-293, Jun. 2005.

[7] O. M. Chepurna et al., "Selective irradiation of superficial tumours depending on the photosensitiser fluorescence in the tissue," in Information Technology in Medical Diagnostics II - Proceedings of the International Scientific Internet Conference on Computer Graphics and Image Processing and 48th International Scientific and Practical Conference on Application of Lasers in Medicine an, 2019.

[8] A. Erkiert-Polguj, A. Halbina, I. Polak-Pacholczyk, and H. Rotsztejn, "Light-emitting diodes in photodynamic therapy in non-melanoma skin cancers - Own observations and literature review," Journal of Cosmetic and Laser Therapy. 2016.

[9] L. Brancaleon and H. Moseley, "Laser and non-laser light sources for photodynamic therapy.," Lasers Med. Sci., vol. 17, no. 3, pp. 173-186, 2002.

[10] J. Neupane, S. Ghimire, S. Shakya, L. Chaudhary, and V. P. Shrivastava, "Effect of light emitting diodes in the photodynamic therapy of rheumatoid arthritis," Photodiagnosis Photodyn. Ther., vol. 7, no. 1, pp. 44-49, Mar. 2010.

[11] H. Xu et al., "Effects of light irradiation upon photodynamic therapy based on 5-aminolevulinic acid-gold nanoparticle conjugates in K562 cells via singlet oxygen generation," Int. J. Nanomedicine, vol. 7, pp. 50295038, 2012.

[12] D. Chen et al., "Light-Emitting Diode-Based Illumination System for In Vitro Photodynamic Therapy," Int. J. Photoenergy, vol. 2012, pp. 1-6, Mar. 2012.

[13] D. E. Dolmans, D. Fukumura, and R. K. Jain, “TIMELINE: Photodynamic therapy for cancer," Nat. Rev. Cancer, 2003.

[14] F. F. Sperandio et al., "Photoinduced electron-transfer mechanisms for radical-enhanced photodynamic therapy mediated by water-soluble decacationic C70 and C84O2 Fullerene Derivatives," Nanomedicine Nanotechnology, Biol. Med., 2013.

[15] H.-Q. Liu, Y.-W. An, A.-Z. Hu, M.-H. Li, and G.-H. Cui, "Photodynamic Therapy Enhanced the Antitumor Effects of Berberine on HeLa Cells," Open Chem., vol. 17, no. 1, pp. 413-421, Jun. 2019.

[16] N. Luiza Andreazza, C. Vevert-Bizet, G. Bourg-Heckly, F. Sureau, M. José Salvador, and S. Bonneau, "Berberine as a photosensitizing agent for antitumoral photodynamic therapy: Insights into its association to low density lipoproteins," Int. J. Pharm., 2016.

[17] A. Grebinyk et al., "C 60 fullerene accumulation in human leukemic cells and perspectives of LED-mediated photodynamic therapy," Free Radic. Biol. Med., 2018.

[18] U. Ritter et al., "Structural features of highly stable reproducible C60 fullerene aqueous colloid solution probed by various techniques," Fullerenes Nanotub. Carbon Nanostructures, 2015.

[19] J. Carmichael, W. G. Degraff, A. F. Gazdar, J. D. Minna, and J. B. Mitchell, "Evaluation of a Tetrazolium-based Semiautomated Colorimetric Assay : Assessment of Chemosensitivity Testing Evaluation of a Tetrazoliumbased Semiautomated Colorimetrie Assay : Assessment," Am. Assoc. Cancer Res., 1987.

[20] C. L. Kuo, C. W. Chi, and T. Y. Liu, "Modulation of apoptosis by berberine through inhibition of cyclooxygenase-2 and Mcl-1 expression in oral cancer cells," In Vivo (Brooklyn)., 2005.

[21] J. B. Patil, J. Kim, and G. K. Jayaprakasha, "Berberine induces apoptosis in breast cancer cells (MCF-7) through mitochondrial-dependent pathway," Eur. J. Pharmacol., 2010.

[22] J. Zhang et al., "Berberine potently attenuates intestinal polyps growth in ApcMin mice and familial adenomatous polyposis patients through inhibition of Wnt signalling," J. Cell. Mol. Med., 2013. 